\title{
Cholesterol Granuloma
}

National Cancer Institute

\section{Source}

National Cancer Institute. Cholesterol Granuloma. NCI Thesaurus. Code C4082.

A cystic inflammatory lesion that is comprised of fluids, lipids, and cholesterol crystals, and which is surrounded by a fibrous lining. 